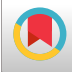

\title{
Prevalence of Transfusion Transmissible Infections Among Blood Donors in South Khorasan Province, Iran: An 11-Year Study
}

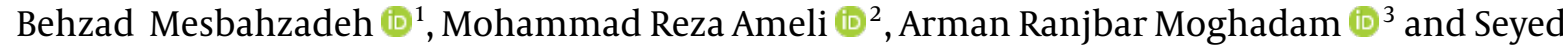 \\ Mehdi Sajjadi (iD) ${ }^{4, *}$ \\ ${ }^{1}$ Cardiovascular Diseases Research Center, Birjand University of Medical Sciences, Birjand, Iran \\ ${ }^{2}$ Iranian Blood Transfusion Organization Research Center, South-Khorasan Blood Transfusion Service, Birjand, Iran \\ ${ }^{3}$ Student Research Committee, Birjand University of Medical Sciences, Birjand, Iran \\ ${ }^{4}$ Cellular and Molecular Research Center, Birjand University of Medical Sciences, Birjand, Iran \\ "Corresponding author: Cellular and Molecular Research Center, Birjand University of Medical Sciences, Birjand, Iran. Email: mehdi.sadjadi@bums.ac.ir
}

Received 2021 July 21; Revised 2021 October 08; Accepted 2021 October 27.

\begin{abstract}
Background: Transfusion transmissible infections (TTIs) are the most frequent complication of blood transfusions. This fact stresses the need for regular evaluation and monitoring of TTIs in blood donors.

Objectives: This study was done to determine the prevalence of the hepatitis B virus (HBV), hepatitis C virus (HCV), human immunodeficiency virus (HIV), and syphilis among blood donors at the South Khorasan Transfusion Center (SKBTC) in South Khorasan Province, Iran. This report is the first of its kind that has been performed in this region.

Methods: A retrospective study was carried out on 165,267 blood donors at the SKBTC from 2006 to 2016. Data were analyzed on the metrics of donation status, age, gender, educational level, and serologic results for the infectious markers. Statistical analysis was performed using SPSS software (version 16.0).

Results: The overall seroprevalence rates of HBV, HCV, and HIV infections per 100,000 donations were 247, 21, and 0.6, respectively. There was no positive donor for syphilis. HBV and HCV infections in first-time donors were present at significantly higher rates than in regular and repeat donors $(\mathrm{P}<0.001$ and $\mathrm{P}=0.003$, respectively). Although gender was not found to be significantly associated with $\mathrm{HBV}$ and $\operatorname{HCV}(\mathrm{P}=0.32)$, there was a significant relationship between younger age $(\mathrm{P}<0.001)$ as well as lower educational level and hepatitis agents $(\mathrm{P}<0.001)$. Moreover, being single evinced a significant association with HCV seropositivity $(\mathrm{P}=0.001)$.

Conclusions: This report found a decreased prevalence of TTIs relative to the most of previous reports. This decrease may have resulted from public health programs, improved donor selection, improved recruitment of repeat/regular donors, and the use of highly sensitive kits for the screening procedure.
\end{abstract}

Keywords: Iran, Syphilis, HCV, HBV, HIV, Blood Donors

\section{Background}

Each year, about 75 million blood units are collected in the world (1). About one-third of the world's population will require blood/blood products throughout their life span. Although blood transfusion can be a lifesaving procedure, it can also have disastrous health and economic consequences on its recipients, their families, and society (2-4). Each recipient is at risk of contracting transfusiontransmissible infections (TTIs), such as hepatitis B virus (HBV), hepatitis C virus (HCV), human immunodeficiency virus (HIV), and Treponema pallidum (syphilis) (3). HBV is the main cause of chronic liver morbidity (5), while HCV is the primary cause of post-transfusion hepatitis (6). The estimated global prevalence of HBV and HCV infections is about 257 million and 71 million, respectively (7). The overall prevalence of $\mathrm{HBV}, \mathrm{HCV}$, and HIV was reported to be 0.56 , 0.013 , and $0.004 \%$, respectively. In Iran, screening of volunteer blood donations for HBV, HIV, and HCV became mandatory in 1974,1989 , and 1996, respectively (8).

Despite considerable progress made over the last few decades in the prevention of TTIs via blood transfusion by donor education, utilizing the pre-donation questionnaires, voluntary donation, donor deferral, and advanced donor screening assays (7, 9-11), TTIs have not been totally eliminated $(7,12,13)$. Therefore, the safety of transfusions is still an issue of interest (2). Evaluating TTI prevalence and incidence is a critical approach to identify potential changes in the epidemiology of these infections in the population and monitoring the effectiveness of donor educa- 
tion as well as selection and screening procedures $(14,15)$.

\section{Objectives}

The aim of the present study was to evaluate the prevalence of four TTI infections among first-time, regular, and repeat blood donors who attended the South Khorasan blood transfusion service (SKBTC), South Khorasan province Iran, from 2006 to 2016.

\section{Methods}

In this retrospective study, 165267 healthy, voluntary, non-remunerated blood donors referring to SKBTC from 2006 to 2016 were selected based on the standard predonation screening procedure. Donors were categorized into three different groups: first-time donors who donated for the first and only time; repeat donors who had a history of the previous donation but the time between two donations was longer than a year; and regular donors who were donating more than once a year.

All donations were screened for the presence of HBsAg, HCV Ab, and HIV (Ag/Ab) by third-generation enzymelinked immunosorbent assay (ELISA) kits, while syphilis was screened by rapid plasma reagin (RPR) test based on the Iranian Blood Transfusion Organisation (IBTO) instructions. The initially positive samples were re-examined, and the repeatedly positive ones were considered seropositive for infection. Repeatedly reactive donations were then confirmed with hepatitis B core antibody (anti-HBc) and HBsAg neutralization tests, HCV recombinant immunoblot assay (RIBA), and HIV western blot. HIV-negative samples evidenced by western blot were tested by HIV p 24 antigen and monoclonal neutralization assay if the results were repeatedly reactive. Syphilis was confirmed using the Treponema pallidum Hemagglutination (TPHA) test. The applied kits for screening and confirmatory tests are given in Table 1.

Statistical analysis was performed using SPSS software (version 16.0). Groups were compared by the chi-square test. Logistic regression analyses were conducted to examine the correlates of TTIs prevalence. P-values of less than 0.05 were considered statistically significant.

\section{Results}

Over an 11-year period, a total of 165267 donations were collected from volunteer donors, with a mean of 15024 donations per year. The donor population consisted of 152098 (94.23\%) males with a mean age of 29.5 years and 13169
(5.77\%) females with a mean age of 32.8 years, making a male/female ratio of 11.5 to 1 . The most frequent infection in donors was HBV followed by HCV. More specifically, among all donors, 409 donations $(0.25 \%)$ were positive for $\mathrm{HBV}$ and $35(0.02 \%)$ for HCV. The annual rate of seropositivity varied, but there was no discernible upward or downward trend (Table 2). In 2015, there was only one confirmed positive result for HIV -, which came from a repeat donor. Surprisingly, there was no syphilis-positive donor (Table 3). Demographic characteristics and $\mathrm{HBV}$ and HCV positivity among blood donors are shown in Tables 4 and 5, respectively.

HBV infection in first-time donors was significantly higher than in regular $\left(\chi^{2}=64.88, \mathrm{P}<0.001, \mathrm{OR}=50.25\right.$; $95 \% \mathrm{CI}, 29.48$ - 85.65) and repeat $\left(\chi^{2}=233.61, \mathrm{P}<0.001\right.$, OR $=61.64 ; 95 \% \mathrm{CI}, 18.59$ - 93.27) donors. In other words, the total prevalence rate per 100,000 for first-time donors was 807 while it was 16 and 20 for regular and repeat donors, respectively; however, the difference in the prevalence of HBV between regular and repeat donors was not statistically significant $\left(\chi^{2}=0.15, \mathrm{P}=0.7, \mathrm{OR}=0.83 ; 95 \% \mathrm{CI}, 0.32\right.$ -2.16).

Regarding HCV infection, the total prevalence rate for first-time and regular donors was 62 per 100,000 donations and 16 per 100,000 donations, respectively, which was statistically significant $\left(\chi^{2}=8.94, \mathrm{P}=0.003, \mathrm{OR}=3.82\right.$; $95 \% \mathrm{CI}, 1.48$ - 9.86). It is noteworthy that no positive case of $\mathrm{HCV}$ was detected among repeat donors.

The prevalence rate in male and female donors for HBV was $0.2 \%(\mathrm{P}=0.32$, $\mathrm{OR}=1.845$; $\mathrm{CI}: 0.60-1.18)$, while it was $0.02 \%$ for $\operatorname{HCV}(\mathrm{P}=0.89, \mathrm{OR}=0.92 ; \mathrm{CI}: 0.28-3.02)$. Therefore, the male to female ratio was not found to be significantly associated with both infections.

There was also a significant relationship between age and $\mathrm{HBV} / \mathrm{HCV}$ seropositivity; donors aged 18 - 24 showed a higher prevalence of HBsAg $(\mathrm{P}<0.001$, OR $=5.21$; CI: 3.95 6.88) and HCV Ab ( $\mathrm{P}<0.001, \mathrm{OR}=3.56$; CI: 1.33 - 9.49).

The seropositivity rates of HBV among married and single donors were found to be $0.25 \%$ and $0.23 \%(\mathrm{P}=0.48$, $\mathrm{OR}$ : $1.09 ; \mathrm{CI}=0.85-1.41$ ), while it was 0.00 and $0.09 \%$ for $\mathrm{HCV}$, respectively ( $\mathrm{P}=0.001, \mathrm{OR}: 0.04 ; \mathrm{CI}=0.01$ - 0.1). Moreover, Tables 3 and 4 show that lower educational level had a meaningful relationship with $\mathrm{HBV}(\mathrm{P}<0.001, \mathrm{OR}: 2.14 ; \mathrm{CI}=1.76$ 2.6) and $\mathrm{HCV}(\mathrm{P}=0.02, \mathrm{OR}: 2.21 ; \mathrm{CI}=1.13$ - 4.31 $)$ infections. In other words, donors with lower educational levels showed a higher prevalence rate of infections than the more educated donors.

\section{Discussion}

In this study, for the first time, the overall frequency of HBV, HCV, HIV, and syphilis infections per 100,000 volun- 


\begin{tabular}{lll}
\hline \multicolumn{2}{l}{ Table 1. The Screening and Confirmatory Test Kits } & \\
\hline Infection & Screening Kits (Manufacturer) & Confirmatory Kits (Manufacturer) \\
\hline HBV & Enzygnost HBs Ag 5.0 (Dade Behring); Enzygnost HBsAg 6.0 (Siemens) & HBsAg confirmatory test: Diasorin; Dade Behring \\
HCV & $\begin{array}{l}\text { Anti-HCV (Avicenna); HCV 3.0 with enhanced SAVe (ORTHO); Hepanostika } \\
\text { HCV Ultra (bioMérieux) }\end{array}$ & HCV RIBA: Inno-LIA HCV Score (Innogenetics); HCV BLOT 3.0 (Genelabs); \\
HIV & Anti-HIV I/II (Biotest); GENSCREEN HIV 1/2 (BIO-RAD); Vironostika HIV & HIV Western Blot; HIV BLOT 2.2 (Genelabs); HIV BLOT 2.2 (MP Diagnostics); \\
& uni-form II Ag/Ab (BioMérieux); GENSCREEN PLUS HIV Ag-Ab (BIO-RAD) & Inno-LIA HIV I/II Score (Innogenetics) \\
\hline
\end{tabular}

\begin{tabular}{lcc}
\hline Table 2. The Annual Prevalence Rates (PRs) per 100,000 Donations for HBV and HCV \\
Infection Among Blood Donors from 2006 to 2016 \\
\hline Year & HBV & HCV \\
\hline $\mathbf{2 0 0 6}$ & 61 & 7 \\
\hline $\mathbf{2 0 0 7}$ & 59 & 2 \\
\hline $\mathbf{2 0 0 8}$ & 51 & 1 \\
\hline $\mathbf{2 0 0 9}$ & 45 & 5 \\
\hline $\mathbf{2 0 1 0}$ & 31 & 0 \\
\hline $\mathbf{2 0 1 1}$ & 30 & 2 \\
\hline $\mathbf{2 0 1 2}$ & 18 & 5 \\
\hline $\mathbf{2 0 1 3}$ & 26 & 3 \\
\hline $\mathbf{2 0 1 4}$ & 38 & 3 \\
\hline $\mathbf{2 0 1 5}$ & 33 & 5 \\
\hline $\mathbf{2 0 1 6}$ & 17 & 2 \\
\hline Total & 409 & 35 \\
\hline
\end{tabular}

teer blood donors referred to the SKBTC were reported.

South Khorasan ("Khorasan-e Jonoubi") is a province located in eastern Iran, and Birjand is the center of the province (1). The social determinant of health status is reported to be low compared to other provinces in Iran (2). However, in comparison with studies on Iranian populations, in our study, the overall prevalence of $\mathrm{HBV}$ was lower than that reported by Amini Kafi-Abad et al. (8), Khedmat et al. (16), and Mohammadali and Pourfathollah (15). Compared to other countries, HBV prevalence in the present study was much lower than that of Turkey (4.1\%) (17), Pakistan (3.9\%) (18), and Germany (19). The prevalence of HBV in our study was similar to that reported by de AlmeidaNeto et al. in Brazil (20); however, it was higher than in France (21) and Australia (22).

The overall frequency of HCV-Ab in our study was lower than in other studies on Iranian blood donors, such as those conducted by Khedmat et al. (16), Amini Kafi-Abad et al. (8), Mohammadali and Pourfathollah (15), Rezvan et al. (23), and Sajjadi et al. (24).

The pooled prevalence of HCV among Iranian blood donors was $0.5 \%$ in a meta-analysis by Khodabandehloo et al. (25), which is substantially higher than our data.

The prevalence of HCV in our province was also lower than that in other countries, such as Germany with $0.07 \%$ (19) and India with $0.84 \%$ (26). As expected, the present result was lower than the prevalence of HCV in the Iranian general population because blood donors are considered to be a healthy population at lower risk of infectious diseases (27). Furthermore, our findings demonstrated that first-time donors had considerably higher frequencies of HBs-Ag and HCV-Ab positivity than repeat and regular donors, which is consistent with prior research in Iranian populations $(8,28)$, as well as in other studies in the United Kingdom (29) and Australia (30).

The most trustworthy group for transfusion is voluntary, repeat, and regular blood donors $(31,32)$. As a result, the observed range in prevalence rates is not surprising. Other studies $(2,33)$ have found that the number of frequent blood donors in their demographic was significantly larger than the number of first-time blood donors.

Only one HIV-positive donor was found in this study who was a regular donor in 2015, which is significantly lower than the rates reported by Khedmat et al. (16), Amini Kafi-Abad et al. (8), and Mohammadali and Pourfathollah (15). HIV prevalence in the general population of Iran was 8.6 per 100000 in 1999 and 23 per 100000 in 2007, both higher than the current study (34). However, Australia, with a negative result for HIV (22), had a lower rate than European countries with roughly 10 per 100000 donors (35), Turkey with 200 per 100000 (4), and India with 390 per 100000 (36).

A surprising result of the present study is that no positive case of syphilis was found during 11 years. Compared to the results obtained in other studies, Yildiz et al. reported that $0.10 \%$ of blood donors in Adana, Turkey were positive (4). Additionally, syphilis positivity was reported as only $0.004 \%$ and $0.01 \%$ in Iran $(15,16)$.

We also found no co-infections in any of the positive donors, which was another amazing result of the present study. However, other studies have reported a significant association between different infections due to their similar modes of transmission $(3,37)$.

The higher frequency of infections in younger donors is consistent with the study by Zheng et al. (13); however, it 


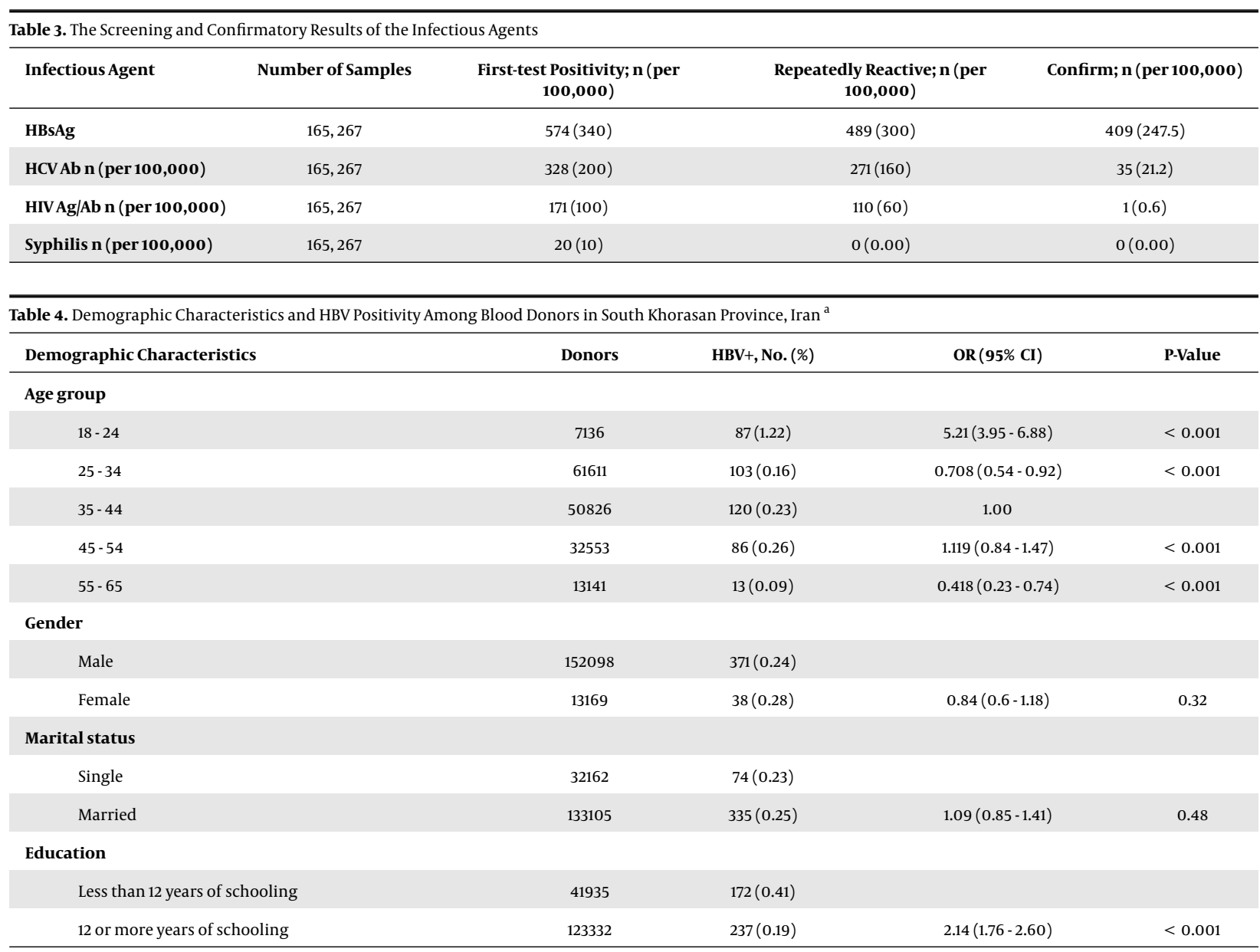

Abbreviations: OR, odds ratio; $\mathrm{CI}$, confidence interval.

${ }^{\mathrm{a}}$ The reference category is $35-44$.

was inconsistent with the reports of Lucky et al. (14).

In this study, no difference was observed regarding the marital status of donors infected with HBV. This finding may be due to the HBV vaccination of the general population. However, the prevalence of the HCV marker in single donors was higher, possibly due to sexual reasons or drug injection; no vaccination is provided for the $\mathrm{HCV}$ infection.

A higher prevalence of $\mathrm{HBV}$ and HCV infections in donors with low educational level accentuates the requirement for the improvement of educational procedures for the risk factors and routes of transmission and also the importance of safe blood donation for donors.

Although the number of females was less than male blood donors, due to their fear of becoming anaemic after blood donation or because they were found to be anemic $(38,39)$ and did not meet the criteria, the prevalence of $\mathrm{HBV}$ and HCV infections was not found to be significantly different for both genders. This was inconsistent with other re- ports from Iran $(8,15)$. However, Noubiap et al. reported a similar result (3).

The lower prevalence of TTIs, especially HIV and syphilis, in our study may have resulted from a conventional culture in South Khorasan Province so that prior to marriage, people contemplate sexual morality and the avoidance of high-risk behaviors, such as sexual intercourse with several partners. Improved recruitment of low-risk donors may be another reason for this issue. Furthermore, the number of donors in this study was much lower than similar Iranian studies, such as Mohammadali and Pourfathollah (15), in which more than 2 million blood donors were investigated. However, the prevalence of syphilis in that study was just $0.004 \%$.

The remarkable divergence in TTIs prevalence among blood donors in different populations could be due to a variation in the study population, sample sizes, quality of public health services, different lifestyles, habits, and rates 


\begin{tabular}{|c|c|c|c|c|}
\hline Demographic characteristics & Donors & HCV+, No. (\%) & OR $(95 \% \mathrm{CI})$ & P-Value \\
\hline \multicolumn{5}{|l|}{ Age group* } \\
\hline $18-24$ & 7136 & $6(0.08)$ & $3.56(1.33-9.49)$ & \\
\hline $25-34$ & 61611 & $11(0.01)$ & $0.756(0.33-1.71)$ & $<0.001$ \\
\hline $35-44$ & 50826 & $12(0.02)$ & 1.00 & $<0.001$ \\
\hline $45-54$ & 32553 & $6(0.01)$ & $0.78(0.29-2.08)$ & \\
\hline $55-65$ & 13141 & $0(0.00)$ & - & $<0.001$ \\
\hline \multicolumn{5}{|l|}{ Gender } \\
\hline Male & 152098 & $32(0.02)$ & & \\
\hline Female & 13169 & $3(0.02)$ & $0.92(0.28-3.02)$ & 0.89 \\
\hline \multicolumn{5}{|l|}{ Marital status } \\
\hline Single & 32162 & $30(0.09)$ & & \\
\hline Married & 133105 & $5(0.00)$ & $0.04(0.01-0.1)$ & $<0.001$ \\
\hline \multicolumn{5}{|l|}{ Education } \\
\hline$\leq 12$ years of schooling & 41935 & $15(0.03)$ & & \\
\hline$\geq 12$ years of schooling & 123332 & $20(0.01)$ & $2.21(1.13-4.31)$ & 0.02 \\
\hline
\end{tabular}

Abbreviations: OR, odds ratio; $\mathrm{CI}$, confidence interval.

${ }^{a}$ The reference category is $35-44$.

of high-risk behaviors in different geographic regions, as well as different kits used for determining the infectious agents $(11,40)$.

\subsection{Conclusion}

It was the first report from South Khorasan province. The risk factors for HBV and HCV infection were younger age, being a first-time donor, and being less educated. TTI rates were found to be low among blood donors in South Khorasan Province, probably owing to improvements in blood donor screening methods and the region's traditional culture. Continuous monitoring of the prevalence of TTIs among blood donors may aid in the recruitment of donors at lower risk leading to improved blood safety. However, it is necessary to realize that it is never possible to eradicate all risks of TTIs; therefore, we have to continue to improve the quality of the screening program as often as we can.

\section{Acknowledgments}

This project was accepted by the Birjand University of Medical Sciences (project No. 4666). We gratefully acknowledge all the staff of SKBTC.

\section{Footnotes}

Authors' Contribution: Behzad Mesbahzadeh, literature search, data acquisition, writing of the manuscript; Mohammadreza Ameli, conceptualization and data collection; Arman Ranjbar Moghadam, literature search, statistical analysis; Seyed Mehdi Sajjadi, conceptualization, design of the study, editing, and review.

Conflict of Interests: The authors have no potential conflicts of interests.

Ethical Approval: IR.BUMS.REC.1396.248

Funding/Support: None to declare.

\section{References}

1. Klein HG, Spahn DR, Carson JL. Red blood cell transfusion in clinical practice. Lancet. 2007;370(9585):415-26. doi: 10.1016/S01406736(07)61197-0. [PubMed: 17679019].

2. Kafi-abad SA, Rezvan H, Abolghasemi H. Trends in prevalence of hepatitis B virus infection among Iranian blood donors, 1998-2007. Transfus Med. 2009;19(4):189-94. doi: 10.1111/j.1365-3148.2009.00935.x. [PubMed: 19708860].

3. Noubiap JJ, Joko WY, Nansseu JR, Tene UG, Siaka C. Sero-epidemiology of human immunodeficiency virus, hepatitis $B$ and $C$ viruses, and syphilis infections among first-time blood donors in Edea, Cameroon. Int J Infect Dis. 2013;17(10):e832-7. doi: 10.1016/j.ijid.2012.12.007. [PubMed: 23317526].

4. Yildiz SM, Candevir A, Kibar F, Karaboga G, Turhan FT, Kis C, et al. Hepatitis B, Hepatitis C, Human immunodeficiency virus and syphilis frequency among blood donors: A single center study. 
Transfus Apher Sci. 2015;53(3):308-14. doi: 10.1016/j.transci.2015.05.022. [PubMed: 26070837].

5. Meena M, Jindal T, Hazarika A. Prevalence of hepatitis B virus and hepatitis $C$ virus among blood donors at a tertiary care hospital in India: A five-year study. Transfusion. 2011;51(1):198-202. doi: 10.1111/j.15372995.2010.02801.x. [PubMed: 20663107].

6. Hassanshahi G, Arababadi MK, Assar S, Hakimi H, Karimabad MN, Abedinzadeh $\mathrm{M}$, et al. Post-transfusion-transmitted hepatitis $\mathrm{C}$ virus infection: A study on thalassemia and hemodialysis patients in southeastern Iran. Arch Virol. 2011;156(7):1111-5. doi: 10.1007/s00705011-0950-y. [PubMed: 21340738].

7. World Health Organization. Global hepatitis report, 2017. Geneva, Switzerland: World Health Organization; 2017.

8. Amini Kafi-Abad S, Rezvan H, Abolghasemi H, Talebian A. Prevalence and trends of human immunodeficiency virus, hepatitis B virus, and hepatitis C virus among blood donors in Iran, 2004 through 2007. Transfusion. 2009;49(10):2214-20. doi: 10.1111/j.1537-2995.2009.02245.x. [PubMed: 19527477].

9. Alter MJ, Kruszon-Moran D, Nainan OV, McQuillan GM, Gao F, Moyer LA, et al. The prevalence of hepatitis $C$ virus infection in the United States, 1988 through 1994. N Engl J Med. 1999;341(8):556-62. doi: 10.1056/NEJM199908193410802. [PubMed: 10451460].

10. Glynn SA, Kleinman SH, Schreiber GB, Busch MP, Wright DI, Smith JW, et al. Trends in incidence and prevalence of major transfusiontransmissible viral infections in US blood donors, 1991 to 1996. Retrovirus Epidemiology Donor Study (REDS). JAMA. 2000;284(2):229-35. doi: 10.1001/jama.284.2.229. [PubMed: 10889598].

11. Matee MI, Magesa PM, Lyamuya EF. Seroprevalence of human immunodeficiency virus, hepatitis B and C viruses and syphilis infections among blood donors at the Muhimbili National Hospital in Dar es Salaam, Tanzania. BMC Public Health. 2006;6:21. doi: 10.1186/1471-24586-21. [PubMed: 16445860]. [PubMed Central: PMC1373616].

12. ALGani FA. International Journal of Biological \& Medical Research. Int J Biol Med Res. 2011;2:1175-7.

13. Zheng X, Ding W, Li G, Wu Y, Wu D, Zhu H, et al. Seroprevalence of transfusion-transmissible infectious agents among volunteer blood donors between 2006 and 2012 in Zhejiang, China. Blood Transfus. 2015;13(3):401-10. doi: 10.2450/2015.0271-14. [PubMed: 26192780]. [PubMed Central: PMC4614291].

14. Lucky TT, Seed CR, Keller A, Lee J, McDonald A, Ismay S, et al. Trends in transfusion-transmissible infections among Australian blood donors from 2005 to 2010. Transfusion.2013;53(11):2751-62. doi: 10.111//trf.12144. [PubMed: 23461827].

15. Mohammadali F, Pourfathollah AA. Changes in frequency of HBV, HCV, HIV and syphilis infections among blood donors in Tehran province 2005 - 2011. Arch Iran Med. 2014;17(9):613-20. [PubMed: 25204477].

16. Khedmat H, Alavian S, Miri SM, Amini M, Aboighasemi H, Hajibeigi $B$, et al. Trends in seroprevalence of hepatitis B, hepatitis C, HIV, and syphilis infections in Iranian blood donors from 2003 to 2005. Hepat Mon. 2009;9(1):24-8.

17. Gurol E, Saban C, Oral O, Cigdem A, Armagan A. Trends in hepatitis $B$ and hepatitis $C$ virus among blood donors over 16 years in Turkey. Eur J Epidemiol. 2006;21(4):299-305. doi: 10.1007/s10654-006-0001-2. [PubMed: 16685581].

18. Ali M, Idrees M, Ali L, Hussain A, Ur Rehman I, Saleem S, et al. Hepatitis B virus in Pakistan: A systematic review of prevalence, risk factors, awareness status and genotypes. Virol J. 2011;8:102. doi: 10.1186/1743422X-8-102. [PubMed: 21375760]. [PubMed Central: PMC3058090].

19. Offergeld R, Ritter S, Hamouda O. [HIV, HCV, HBV and syphilis surveillance among blood donors in Germany 2008-2010]. Bundesgesundheitsblatt Gesundheitsforschung Gesundheitsschutz. 2012;55(8):907-13. German. doi: 10.1007/s00103-012-1516-1. [PubMed: 22842883].

20. de Almeida-Neto C, Sabino EC, Liu J, Blatyta PF, Mendrone-Junior
A, Salles NA, et al. Prevalence of serologic markers for hepatitis B and $C$ viruses in Brazilian blood donors and incidence and residual risk of transfusion transmission of hepatitis C virus. Transfusion. 2013;53(4):827-34. doi: 10.1111/j.1537-2995.2012.03840.x. [PubMed: 22882510]. [PubMed Central: PMC3499633].

21. Servant-Delmas A, Le Gal F, Gallian P, Gordien E, Laperche S. Increasing prevalence of HDV/HBV infection over 15 years in France. J Clin Virol. 2014;59(2):126-8. doi: 10.1016/j.jcv.2013.11.016. [PubMed: 24365475].

22. Polizzotto MN, Wood EM, Ingham H, Keller AJ; Australian Red Cross Blood Service Donor and Product Safety Team. Reducing the risk of transfusion-transmissible viral infection through blood donor selection: The Australian experience 2000 through 2006. Transfusion. 2008;48(1):55-63. doi: 10.1111/j.1537-2995.2007.01482.x. [PubMed: 17894794].

23. Rezvan H, Ahmadi J, Farhadi M, Tardyan S. A preliminary study of prevalence of $\mathrm{HCV}$ infection in healthy Iranian blood donors. Vox Sang. 1994;67(Suppl 2):149.

24. Sajjadi SM, Pourfathollah AA, Mohammadi S, Nouri B, Hassanzadeh R, Rad F. The Prevalence and Trends of Hepatitis B, Hepatitis C, and HIV among Voluntary Blood Donors in Kohgiluyeh and Boyer-Ahmad Transfusion Center, Southwestern Iran. Iran J Public Health. 2018;47(7):944-51. [PubMed: 30181991]. [PubMed Central: PMC6119582].

25. Khodabandehloo M, Roshani D, Sayehmiri K. Prevalence and trend of hepatitis $\mathrm{C}$ virus infection among blood donors in Iran: A systematic review and meta-analysis. J Res Med Sci. 2013;18(8):674-82. [PubMed: 24379843]. [PubMed Central: PMC3872606].

26. Bhattacharya P, Chandra PK, Datta S, Banerjee A, Chakraborty S, Rajendran K, et al. Significant increase in HBV, HCV, HIV and syphilis infections among blood donors in West Bengal, Eastern India 2004-2005: exploratory screening reveals high frequency of occult HBV infection. World J Gastroenterol. 2007;13(27):3730-3. doi: 10.3748/wjg.v13.i27.3730. [PubMed: 17659734]. [PubMed Central: PMC4250646].

27. Merat S, Rezvan H, Nouraie M, Jamali A, Assari S, Abolghasemi H, et al. The prevalence of hepatitis B surface antigen and anti-hepatitis B core antibody in Iran: A population-based study. Arch Iran Med 2009;12(3):225-31. [PubMed: 19400598].

28. Keshvari M, Sharafi H, Alavian SM, Mehrabadi H, Zolfaghari S. Prevalence and trends of transfusion-transmitted infections among blood donors in Tehran, Iran from 2008 to 2013. Transfus Apher Sci. 2015;53(1):38-47. doi: 10.1016/j.transci.2015.03.003. [PubMed: 25892591].

29. Brant LJ, Reynolds C, Byrne L, Davison KL. Hepatitis B and residual risk of infection in English and Welsh blood donors, 1996 through 2008 Transfusion. 2011;51(7):1493-502. doi: 10.1111/j.1537-2995.2011.03108.x. [PubMed: 21470235].

30. O'Brien SF, Fan W, Xi G, Yi QL, Goldman M, Fearon MA, et al. Declining hepatitis $C$ rates in first-time blood donors: Insight from surveillance and case-control risk factor studies. Transfusion. 2008;48(5):902-9. doi: 10.1111/j.1537-2995.2007.01618.x. [PubMed: 18208409].

31. Lattimore S, Wickenden C, Brailsford SR. Blood donors in England and North Wales: Demography and patterns of donation. Transfusion. 2015;55(1):91-9. doi: 10.1111/trf.12835. [PubMed: 25178387].

32. Van der Bij AK, Coutinho RA, Van der Poel CL. Surveillance of risk profiles among new and repeat blood donors with transfusion-transmissible infections from 1995 through 2003 in the Netherlands. Transfusion. 2006;46(10):1729-36. doi: 10.1111/j.15372995.2006.00964.x. [PubMed: 17002629].

33. Farzadegan H, Harbour C, Ala F. The prevalence of hepatitis B surface antigen and its antibody in blood donors and high risk groups in Iran. Vox Sang. 1979;37(3):182-6. doi: 10.1111/j.1423-0410.1979.tb02289.x. [PubMed: 494588].

34. Massarrat $M$, Tahaghoghi-Mehrizi S. Iranian national health survey: A brief report. Arch Iranian Med. 2002;5(2):73-9. 
35. Likatavicius G, Hamers FF, Downs AM, Alix J, Nardone A. Trends in HIV prevalence in blood donations in Europe, 1990-2004. AIDS. 2007;21(8):1011-8. doi: 10.1097/QAD.ob013e3280b07dd7. [PubMed: 17457095].

36. Gupta N, Kumar V, Kaur A. Seroprevalence of HIV, HBV, HCV and syphilis in voluntary blood donors. Indian J Med Sci. 2004;58(6):2557. [PubMed: 15226580].

37. Buseri FI, Muhibi MA, Jeremiah ZA. Sero-epidemiology of transfusiontransmissible infectious diseases among blood donors in Osogbo, south-west Nigeria. Blood Transfus. 2009;7(4):293-9. doi: 10.2450/2009.0071-08. [PubMed: 20011640]. [PubMed Central: PMC2782806].
38. Javadzadeh Shahshahani H. Why don't women volunteer to give blood? A study of knowledge, attitude and practice of women about blood donation, Yazd, Iran, 2005. Transfus Med. 2007;17(6):451-4. doi: 10.1111/j.1365-3148.2007.00803.x. [PubMed: 18067649].

39. Mousavi F, Tavabi AA, Golestan B, Ammar-Saeedi E, Kashani H, Tabatabaei R, et al. Knowledge, attitude and practice towards blood donation in Iranian population. Transfus Med. 2011;21(5):308-17. doi: 10.1111/j.1365-3148.2011.01080.x. [PubMed: 21696474].

40. Taherkhani R, Farshadpour F. Epidemiology of hepatitis C virus in Iran. World J Gastroenterol. 2015;21(38):10790-810. doi: 10.3748/wjg.v21.i38.10790. [PubMed: 26478671]. [PubMed Central: PMC4600581]. 